\title{
VOCÊ NÃO ESTÁ SOZINHO! ESTRATÉGIAS BIOPOLÍTICAS EM DISCURSOS SOBRE A SEGURANÇA DE SUJEITOS LGBTQ+
}

\author{
Glênio Rodrigues Ribeiro Neto* \\ Francisco Vieira da Silva*
}

\begin{abstract}
RESUMO: Segundo pesquisas recentes realizadas pelo Grupo Gay da Bahia (GGB), um LGBTQ+ é morto a cada 20 horas no Brasil, o que evidencia nosso país como um dos que mais mata esses sujeitos no mundo, superando, inclusive, países em que essas sexualidades são condenadas. Pensando por esse viés, é importante destacar que as eleições de 2018 fizeram emergir uma série de discursos LGBTQfóbicos partindo do atual presidente da república, Jair Bolsonaro. Os dados estatísticos do GGB e a falta de comprometimento anunciada ainda em campanha pelo presidente, fizeram com que associações não governamentais, sites e aplicativos gays propusessem as suas próprias medidas cautelares, a fim de que esse número agravante de mortes não aumentasse. Tomando esse pressuposto como base, o presente estudo objetiva analisar os discursos que enunciam acerca da segurança dos sujeitos LGBTQ+, a partir de um olhar arqueogenealógico proposto por Michel Foucault, considerando os conceitos de Biopoder e Biopolítica que irrompem nas materialidades destacadas. Por conseguinte, as análises aproximam-se da lógica da sociedade de controle no que tange o surgimento de medidas de proteção para os sujeitos que não obedecem a lógica binária de gênero e de orientação sexual.
\end{abstract}

PALAVRAS-CHAVE: Segurança; LGBTQ+; Bipoder; Biopolítica.

\footnotetext{
* Mestrando do Programa de Pós-Graduação em Letras (PPGL) da Universidade do Estado do Rio Grande do Norte (UERN).

** Doutor em Linguística pela Universidade Federal da Paraíba (UFPB). Docente da Universidade Federal Rural do Semiárido (Ufersa) e do Programa de Pós-Graduação em Letras (PPGL) da Universidade do Estado do Rio Grande do Norte (Uern) e do Programa de Pós-Graduação em Ensino (Posensino) da associação entre a Universidade do Estado do Rio Grande do Norte (Uern), a Universidade Federal Rural do Semi-Árido (Ufersa) e o Instituto Federal de Educação, Ciência e Tecnologia do Rio Grande do Norte (IFRN).
} 
Não vou combater nem discriminar, mas se eu vir dois homens se beijando na rua, vou bater. Jair Bolsonaro

\section{Notas introdutórias}

Anualmente o Grupo Gay da Bahia (GGB) elabora um relatório com estatísticas nacionais sobre as mortes dos sujeitos LGBTQ+. O relatório mais atualizado refere-se ao ano de 2018 e mostra um crescente número de assassinatos e suicídios desse público, destacando o Brasil como o país que mais mata LGBTQ+ no mundo, superando inclusive, países do Oriente Médio e da África, nos quais existe pena de morte para tais sujeitos. Segundo dados do grupo, a cada 20 horas um LGBTQ+ é assassinado, o que corresponde a um aumento de 30\% em relação aos últimos anos e, acaba por fazer surgir uma discussão acerca da vulnerabilidade desse público.

As causas das mortes diversificam-se, sendo as principais desencadeadas por tiros, arma branca, suicídio, espancamento e asfixia, com isso, podemos identificar que a maioria dos homossexuais são vítimas de assassinatos. Os crimes mais comuns são noticiados de forma bárbara, motivados, muitas vezes, pela LGBTQfobia, como o caso da travesti Dandara ${ }^{1}$, que em 2017 foi espancada e morta por arma de fogo, além de ter tido o corpo jogado em uma vala na cidade de Fortaleza, Ceará. Na ocasião todo o seu suplício foi gravado por uma câmera de celular e postado nas redes sociais.

No caso das leis que asseguram os direitos específicos que os sujeitos LGBTQ+ necessitam, aquece uma série de discursos que apontam para a necessidade de um investimento político no que diz respeito às vivencias particulares desse público, a fim de reverter a exclusão social e a diminuição da violência (SANTOS, 2010). A Organização Mundial de Saúde (OMS) entende por violência o uso intencional da força no intuito de causar lesões ou danos (KRUG, et al. 2002), observando também que é algo que avança e que se torna

\footnotetext{
${ }^{1}$ Disponível em: <http://g1.globo.com/ceara/noticia/2017/03/apos-agressao-dandara-foi-morta-com-tiro-dizsecretario-andre-costa.html $>$. Acesso em: 04 jan. 2019.
} 
cotidiano, ponderando os números colhidos anualmente (SILVA; SANCHEZ, 2014). Uma das pilastras que escora a LGBTQfobia é a heteronormatividade, pois é dado a heterossexualidade o patamar de sexualidade dominante, marginalizando as outras manifestações de gênero e sexualidade (RUBIN, 1984), dentre outros discursos que poderiam ser arrolados aqui e também apontam uma preocupação cotidiana em se promover estratégias de saberpoder para motivar a diminuição dos números de assassinatos e espancamentos aos sujeitos LGBTQ+, promovendo assim a segurança desse público em específico.

A criminalização da homofobia transita no senado desde 2001, a exemplo da PL 5003/2001, apresentada por Iara Bernadi do Partido dos Trabalhadores (PT), em sua gestão como deputada federal do estado de São Paulo. O Projeto de Lei caminhou em diversas instâncias do Superior Tribunal Federal, sofrendo alterações na redação da lei por diversas vezes. O mais recente projeto de lei, que caminha em busca de aprovação, é o PL 122/2006, o qual ainda sofre alteração, na tentativa de agradar tanto a bancada evangélica quanto aos órgãos representantes dos LGBTQ+ no Brasil. Apesar do projeto seguir em constante alteração, o foco central é que a Lei de criminalização da homofobia se equipare a do racismo, promovendo danos ao autor do crime. A última audiência para a verificação da lei foi agendada para o dia 12 de dezembro de 2018, mas foi cancelada e adiada para fevereiro de 20192. Assim, as ações que buscam preservar e garantir a vida dos sujeitos LGBTQ+ provêm, principalmente, de grupos e associações de apoio não-governamentais.

A recente onda de discursos autoritários e LGBTQfóbicos, motivada notadamente pelo discurso do atual presidente Jair Bolsonaro (PSL) e de seus apoiadores, fez com que no decurso da campanha eleitoral de 2018 diversos órgãos de apoio à população LGBTQ+ e entidades ligadas a esse público, propusessem medidas de segurança a fim de assegurar a vida dessa população. São sobre essas medidas que volvemos nosso olhar neste texto.

\footnotetext{
2 Disponível em: https://www.huffpostbrasil.com/2018/05/17/a-origem-do-dia-de-combate-a-homofobia-e-ofuturo-do-movimento-lgbt-no-brasil_a_23437142/. Acesso em: 04 jan. 2019
} 
Nesse sentido, o propósito deste escrito é o de analisar os discursos que enunciam acerca da segurança dos sujeitos LGBTQ+, com o intuito de investigar o funcionamento das estratégias biopolíticas no que tange à manutenção e à seguridade das vítimas de lgbtqfobia no Brasil. Consideramos a emergência dos discursos no momento presente, o qual se encontra marcado pelas relações de saber-poder que dedicam uma atenção específica à seguridade dos sujeitos LGBTQ+, no intuito de proteger a população através de medidas de proteção e de alerta, baseadas na lógica da sociedade de controle.

Preocupados com o cenário político atual, diversos órgãos não governamentais fizeram circular diferentes materialidades que visavam orientar a população LGBTQ+, as quais serviram de corpus para este trabalho: (i) folder sobre os direitos transsexuais nos momentos de revista íntima produzido pela associação sem fins lucrativos RENOSPLGBTQ+; (ii) comunicado apresentado no aplicativo Grindr; (iii) folder contendo elucubrações em casos de presenciar agressões aos LGBTQ+, produzidos pela RENOSPLGBTQ+. Os enunciados presentes nestas materialidades nos ajudarão a entender como funcionam as estratégias biopolíticas quando se tratam de atender um público específico, que tem grande histórico de mortes e agressões.

Tomando essas problematizações como base, a discussão deste artigo será promovida a partir das teorizações de Michel Foucault (2005; 2007), acerca do biopoder e da biopolítica. De acordo com Foucault (2005), o biopoder decorre de uma tecnologia de poder que busca a estatização do corpo e da vida dos sujeitos, preocupando-se com os índices populacionais, de natalidade, mortalidade, expectativa de vida e longevidade, uma vez que, se considera governar para promover saúde de qualidade, bem-estar e segurança. Ainda como eixo norteado pelo biopoder, as biopolíticas configuram-se como estratégias de poder que se propõem a administrar o corpo populacional, promovendo políticas públicas a fim de gerir a população, considerando critérios relacionados à manutenção da vida e do bem-estar do corpo populacional.

Ademais, colocamos em pauta neste trabalho a Análise do discurso, a fim subsidiar nossas análises, acionando a perspectiva teórico-metodológica de Michel Foucault que une 
duas fases do autor: a arqueológica e a genealógica. Na primeira, o autor francês debruçouse a entender os saberes que tomam os sujeitos como objeto de estudo; na segunda, Foucault buscou compreender as estratégias de poder que incidem sobre a construção dos sujeitos, através da norma, da governamentalidade, da disciplina e do biopoder. A junção desses dois momentos do pensamento foucaultiano permite-nos vislumbrar um olhar arqueogenealógico de análise.

No que se refere à organização deste artigo, além desta seção de caráter introdutório, o texto encontra-se estruturado em três partes: na próxima seção, refletiremos acerca dos postulados de Foucault, com o propósito de subsidiar a análises das materialidades, a partir das noções de discurso, enunciado e formação discursiva, além das elucubrações do autor acerca do biopoder, das biopolíticas e do dispositivo de segurança. Posteriormente, procedemos com as análises do corpus selecionado e, no último tópico, tecemos algumas considerações finais.

\section{Uma imersão na teoria foucaultiana}

A vasta obra de Michel Foucault, elaborada ao longo de toda sua frutífera vida intelectual, fez com que estudiosos dividissem o pensamento do autor em três fases: a genealógica, a arqueológica e a ética. Aqui, trilharemos um breve percurso acerca do momento arqueológico e genealógico, que promoverá um olhar arqueogenealógico de análise.

Em Foucault (2010), a arqueologia se refere à própria prática de escavar, de ir mais fundo para desvendar certos paradigmas e questões presentes nos enunciados ditos ou escritos, que emergem em um dado momento histórico, bem como, a forma de dispersão destes. Nas palavras do autor, “[...] deve-se mostrar por que não poderia ser outro, como exclui qualquer outro, como ocupa no meio de outros e relacionado a eles, um lugar que nenhum outro poderia ocupar" (FOUCAULT, 2010, p. 31). Nessa perspectiva, o enunciado é percebido como a matéria prima para o discurso, algo que é essencial e imprescindível para a análise e para a existência dos signos. $\mathrm{O}$ autor supracitado ainda define o enunciado como sendo um evento único, mas que pode ser acionado e revisitado ao longo da história. 
Nesse caso, Foucault (2010a, p. 31/32) define enunciado como sendo algo, "ligado não apenas a situações que o provocam, e as consequências por ele ocasionadas, mas, ao mesmo tempo, e segundo uma modalidade inteiramente diferente, a enunciados que o precedem e o seguem".

Assim sendo, no caso do nosso objeto de estudo, busca-se identificar e analisar não apenas as condições de surgimento dos enunciados que englobam a seguridade da população LGBTQ+, mas como os dizeres acerca dessa questão potencializam os cuidados que esse público deve acionar em momentos de insegurança.

Na perspectiva da Análise do Discurso, a arqueologia foucaultiana faz emergir também o conceito de discurso, o qual abarca uma rede de enunciados que são organizados por uma mesma formação discursiva. Essa formação discursiva é compreendida por Foucault (2010) como sendo regularidades que guiam a dispersão dos enunciados estudados, ou seja, se não existe regularidade nessa dispersão, possivelmente, não haverá discurso. Assim como o próprio nome nos adianta, a regularidade dos discursos é feita por regras, as chamadas regras de formação, pois são a essas regularidades que o discurso se alinha para fazer parte de uma determinada formação discursiva (FOUCAULT, 2010).

As discussões feitas nos parágrafos anteriores decorrem da fase denominada de arqueologia, na qual Foucault procurou investigar os saberes que tomam os sujeitos como objetos de estudo. Na segunda fase, genealógica, o autor pautou seus estudos em torno das relações de poder que incidem sobre o sujeito no Ocidente, buscando compreender como o poder produz sujeitos, por meio da norma, da governamentalidade e do biopoder.

Ao longo do período conhecido como genealógico, Michel Foucault despertou seu olhar para temas como o biopoder e a biopolítica, os quais são vistos em diversas obras do autor nos anos de 1970. Vigiar e punir (1975) e História da sexualidade - a vontade de saber (1976), são exemplos de estudos que apresentam a visão foucaultiana acerca desse poder sobre a vida. Podemos ver também o assunto sendo debatido nas obras originárias dos cursos ministrados pelo autor no Collège de France e, ainda, em conferências e entrevistas cedidas. 
Embora Foucault se debruce de maneira mais contundente acerca do biopoder apenas em 1970, nos cursos ministrados no Collège de France as discussões em torno do poder e de suas relações que perpassam os sujeitos começam a surgir, principalmente nas obras do autor que problematizam a criação da clínica e da psiquiatria, uma vez que, essas manifestações de diagnóstico e cura, provenientes do saber médico, são as primeiras manifestações do poder enquanto gestor da vida (BAZZICALUPO, 2017). É nesse espaço em que Foucault começa a potencializa a discussão do poder sobre a vida, como Bazzicalupo (2017) destaca,

\begin{abstract}
Medicina, clínica e psiquiatria desempenham uma função de organização social decisiva, fornecendo, além de técnicas de controle da população frente a emergências epidemiológicas ou a pragas sociais como o alcoolismo, também instrumentos de classificação que não possuem um caráter individualizante, mas estatísticos, de grupos, de populações [...] de risco a serem marginalizadas ou corrigidas de maneira funcional pela saúde de pública. A natureza incontestada dos saberes médicos sobre a vida permite a esses discursos "verídicos" orientarem as condutas cotidianas, modificar os hábitos de risco, permitindo a intrusão em âmbitos estritamente privados, como o corpo, os hábitos sexuais, a vida reprodutiva. Essas práticas claramente terapêuticas são exemplos de uma área de poder que nunca diz não, mas sempre sim a vida. (BAZZICALUPO, 2017, p 42.)
\end{abstract}

Foucault (2008) explicita como se dá o processo de nascimento das biopolíticas, pois estão ligadas aos índices de natalidade, mortalidade, longevidades, as fragilidades, as possibilidades de epidemia, a prevenção de doença, entre outros recursos que possibilitam assegurar e guiar a população dependendo da sua necessidade. Nos dizeres de Foucault (IBID.), “[...] a regulagem do exercício de poder não me parece ser feito segundo a sabedoria, mas segundo os cálculos, os cálculos das coisas, cálculos das relações, cálculos das riquezas, cálculos dos fatores de poder" (FOUCAULT, 2008, p. 422). Em relação ao nosso objeto de trabalho, verificamos que as biopolíticas, embora criadas de acordo com números e estatísticas, ainda possuem dificuldades em assegurar os corpos que não estão encaixados em padrões heteronormativos, já que essas estratégias ainda são mínimas. 
Deleuze (1990, apud LAURO, 2018), corroborando com os postulados de Foucault ao dissertar sobre as sociedades ocidentais, afirma existir ao longo da história três principais tipos de organização destas: a soberana, a disciplinar e a de controle. O que se daria pela emergência, ao longo do tempo, de diferentes formas de governar e ser governado, podendo o ato do governo ser compreendido enquanto uma arte. O autor mapeia a sociedade sobera datando-a a partir do século XVII até o fim da Segunda Guerra Mundial, no século $\mathrm{XX}$, quando esta abre espaço para uma sociedade disciplinar, que posteriormente é relativamente substituída pela sociedade de controle.

Para Foucault (2008b), a sociedade se organiza principalmente por meio das relações de poder, sendo justamente estas relações um dos principais fatores que a constitui. Ao tratar sobre sociedades soberanas o autor declara que estas polarizavam as relações de morte e vida, na medida em que, o soberano era aquele que gerenciava a vida dos seus súditos, possuindo poder sobre quem devia morrer e quem poderia viver.

As sociedades soberanas foram sendo substituídas, em grande medida devido ao surgimento do sistema capitalista, pelas sociedades que passaram a se estruturar por meio da domesticação dos sujeitos, sendo estas pautadas pela disciplina dos corpos. Pode-se afirmar que a revolução industrial encarcerou os sujeitos em diversas instituições disciplinadoras, como a escola, igreja, hospitais e prisões, as quais domesticavam os corpos dos sujeitos a fim de torná-los aptos para o sistema de produção. A sociedade disciplinar, portanto, teria o desafio de disciplinar de forma individual e coletiva (PANIAGO, S/D).

Deleuze (1990 apud LAURO, 2018) explica que a sociedade extremamente disciplinar entra em declínio, passando à a partir de então, se instalarem as sociedades de controle. Essa nova forma de governar a vida dos sujeitos surge da junção da disciplina com a biopolítica, na medida em que, “a sociedade de controle funciona por redes flexíveis moduláveis, como uma moldagem auto deformante que mudasse continuamente, a cada instante, ou como uma peneira cujas malhas mudassem de um ponto a outro" (DELEUZE, 1999, p. 77, apudLAURO, 2018). Em suma, a sociedade de controle busca massificar, domesticar, guiar os sujeitos a um bem coletivo. O líder dessa sociedade, no entanto, pauta seu trabalho 
no intuito de gerir o bem-estar do corpo populacional, não mais no desígnio do fazer morrer, agora a lógica é fazer viver.

A partir desse momento, podemos entender como as estratégias biopolíticas foram introduzidas na sociedade e em que momento histórico elas começaram a ser massificadas, no sentido de atuar, principalmente, na higienização da população, movendo diversos saberes para, de modo fluído, lançar mão de programas governamentais voltados para cuidados, prevenções, tratamentos e segurança, que asseguram e preservam a vida dos sujeitos. De acordo com Foucault (2007),

Entendia por isso [a biopolítica] a maneira como se procurou, desde o século XVIII, racionalizar os problemas postos à prática governamental pelos fenômenos próprios de um conjunto de viventes constituídos em população: saúde, higiene, natalidade, longevidade, raças.... Sabe-se o lugar crescente que esses problemas ocuparam desde o século XIX e que desafios políticos e econômicos eles vêm constituindo até hoje. (FOUCAULT, 2007, p. 431)

O biopoder pode ser compreendido enquanto o poder sobre a vida, permitindo que as cidades sejam planejadas a partir da problemática da segurança (FOUCAULT, 2007;2004). Foucault, ainda discute acerca de um dispositivo de segurança existente na sociedade ocidental, que essencialmente pauta-se na gestão populacional em suas regularidades, ou seja, na governamentalidade, que seria um,

[...] conjunto constituído pelas instituições, procedimentos, análises e reflexões, cálculos e táticas que permitem exercer esta forma bastante específica e complexa de poder, que tem por alvo a população, por forma principal de saber a economia política e por instrumentos técnicos essenciais os dispositivos de segurança. (FOUCAULT, 1998, p. 291/292)

Os dispositivos de segurança, como visto, permitem entender que o soberano do território é também um administrador desse espaço, trabalhando para regular o corpo populacional, controlando e higienizando a circulação das pessoas. Essa tecnologia, portanto, 
visa um "esquadrinhamento mais rigoroso da população" (FOUCAULT, 2008a, p. 53), com vistas a analisar o que está ocioso na sociedade. Nas palavras do autor supracitado,

Trata-se do surgimento de tecnologias de segurança, seja dentro de mecanismos que são efetivamente de controle social, como no caso da penalidade, seja de mecanismos cuja função é provocar alguma modificação no destino biológico da espécie. (FOUCAULT, 2008b, p. 26)

Em relação a isso, o autor afirma que, “desde o séc. XVII, a revolta urbana é desde já a grande coisa que o governo deve evitar" (FOUCAULT, 2008b, p. 56). Um exemplo que pode ser citado é o fato da escassez de alimentos, uma vez que, os dispositivos de segurança que tratarão das revoltas vão se preocupar em administrar essa escassez para minimizá-la e assim combater os conflitos. Para tanto, na lógica da sociedade moderna, a escassez é vista como algo que pode ser controlado e também evitado, basta produzir dispositivos de segurança que controlem a distribuição, produção e o armazenamento de grãos. O objetivo disso é controlar a população urbana, assegurando sua existência e evitando revoltas. Sendo assim, podemos perceber que o surgimento dos dispositivos de segurança está intrinsecamente ligado aos problemas políticos atuais (FOUCAULT, 2007).

Os dispositivos de segurança, assim como o exemplo citado pelo próprio Foucault, assemelham-se também à luta pela sobrevivência das minorias no Brasil, considerando que negros, mulheres, moradores de periferia e LGBTQ+ são alvos constantes de agressões e estão no topo da lista das pessoas que mais morrem em nosso país, bem como no fim da lista da expectativa de vida ${ }^{3}$. Os dispositivos de segurança gerados, nessa perspectiva, servem para diminuir os índices de mortes e acidentes desse público e assim tentar produzir uma sociedade igualitária.

\footnotetext{
3 Disponível em: <https://veja.abril.com.br/politica/negros-sao-25-vezes-mais-assassinados-do-que-brancosno-brasil-diz-ipea/>. Acesso em: 17 jan. 2019.

Ver mais em: < https://sao-paulo.estadao.com.br/noticias/geral,taxa-de-homicidios-de-negros-e-mais-do-que-odobro-da-de-brancos-no-pais,70002337809>. Acesso em: 17 jan. 2019.

Ver mais em: <https://oglobo.globo.com/sociedade/brasil-segue-no-primeiro-lugar-do-ranking-de-assassinatos-de-transexuais-23234780>. Acesso em: 17 jan. 2019.
} 
As reflexões acerca do biopoder e da biopolítica nos mostram um debate eminente acerca da temática, construído e reconstruído sempre em novas fontes e focos, os quais incidem sobre a produção dos sujeitos contemporâneos e os discursos que os cercam.

\section{Vidas que importam: o desafio da segurança dos LGBTQ+}

Conforme o que foi apresentado nas notas introdutórias, a corpora desta pesquisa compõem-se das seguintes materialidades: (i) folder sobre os direitos transsexuais nos momentos de revista íntima produzido pela associação sem fins lucrativos RENOSPLGBTQ+; (ii) comunicado apresentado no aplicativo Grindr; (iii) folder contendo elucubrações em casos de presenciar agressões aos LGBTQ+ produzidos pela RENOSPLGBTQ+.

A primeira materialidade a ser analisada foi coletada no site da RENOSP-LGBTI ${ }^{4}$ (Rede Nacional de operadores de segurança pública Lésbicas, Gays, Bissexuais, Travestis, Transsexuais e Intersexos). Essa rede é uma associação sem fins lucrativos, pensada em 2010 posteriormente ao II Seminário Nacional de Segurança Pública sem Homofobia (II SENASEP). A rede visa o enfrentamento da LGBTQfobia e a garantia de direitos e liberdade sexual. É constituída por membros da segurança pública nacional, de órgãos como a Marinha, Aeronáutica, Polícia Rodoviária Federal e Polícia Militar de diversos estados e municípios, além de outros segmentos da defesa.

A rede disponibiliza materiais didáticos e informações diárias sobre os avanços e os retrocessos das leis brasileiras que concernem à população LGBTQ+. No ano de 2018, a rede se fortaleceu e se consolidou como uma associação especializada em combate a agressões e a qualquer forma de desrespeito a comunidade, avaliando que o Brasil é o país que mais mata LGBTQ+ segundo fontes da Associação Nacional de Travestis e Transsexuais (ANTRA, 2017).

Figura 1 - Folder sobre a revista de Transsexuais e Travestis

${ }^{4}$ Disponível em: <https://www.renosp-lgbt.org/>. Acesso em: 20 dez. 2018. 




Fonte: RENOSP-LGBTQ+ (2018)

O folder que analisaremos faz referência aos cuidados que transsexuais e travestis devem ter ao serem revistadas em entrada de festas, banheiros, entidades públicas, entre outros locais em que a revista seja necessária. Atualmente a lei exige que mulheres só sejam revistadas por outras mulheres, nesse sentido, entra em conflito as identidades de gênero e como elas são reconhecidas perante o Estado e a lei.

O enunciado do folder já nos direciona a um momento estratégico de cuidado, "Fique Alerta!!!”, este faz com que o leitor tenha maior atenção e saiba dos seus direitos enquanto cidadão, independente da sua identidade de gênero. $O$ verbo no imperativo, além de exprimir uma ordem, no caso do folder denota também um conselho. Alguns estados, a fim de eliminar situações de violências e constrangimentos em público, promoveram o atendimento igualitário de acordo com a sua identidade de gênero, lançaram cartilhas que continha informações para policiais na hora de revistar travestis e transsexuais ${ }^{5}$.

O restante do enunciado, "Travestis e mulheres transsexuais devem ser revistadas por agentes femininas sempre que possível", traz orientações para que a identidade destas

\footnotetext{
${ }^{5}$ Disponível em: <https://m.noticias.ne10.uol.com.br/noticia/2016/04/11/cartilha-orienta-pms-sobre-procedimentos-ao-revistar-publico-lgbt-608039.php>. Acesso dia: 18 jan. 2019.
} 
seja preservada e se obtenha um melhor atendimento, eliminando qualquer forma de preconceito ou que ponha esses sujeitos em situações vexatórias. Podemos observar que o enunciado da materialidade se pauta sob uma lógica biopolítica através de uma tecnologia de governamentalidade que busca alertar o público em questão e torná-lo apto à lógica biopolítica da sociedade atual (FOUCAULT, 2008). De forma, acaba por orientar essa comunidade sobre a diversidade sexual e de gênero, guiando-os a saber como lhe dar com o outro sem constrange-lo, bem como também acaba por contribuir para o bem-estar, segurança e integridade dos sujeitos transexuais e travestis.

O restante do enunciado emite a seguinte afirmação, "Respeitar a identidade de gênero é um dever do estado”. A cartilha foi distribuída por alguns estados brasileiros e traz elementos importantes quanto ao respeito a diversidade, orientando sobretudo todos os servidores que, de modo direto ou indireto, trabalham em setores que lidam diretamente com pessoas. O que acaba por chamar a atenção destes para a percepção acerca da diferenciação entre identidade de gênero e orientação sexual. Sendo isso bastante relevante, uma vez que, segundo a constituição de 1988, Art. $5^{\circ}$ "Todos são iguais perante a lei, sem distinção de qualquer natureza", completando ainda que todos têm “[...] direito à vida, à liberdade, à igualdade, à segurança e à propriedade".

Figura 2 - Alerta de segurança de aplicativo gay.

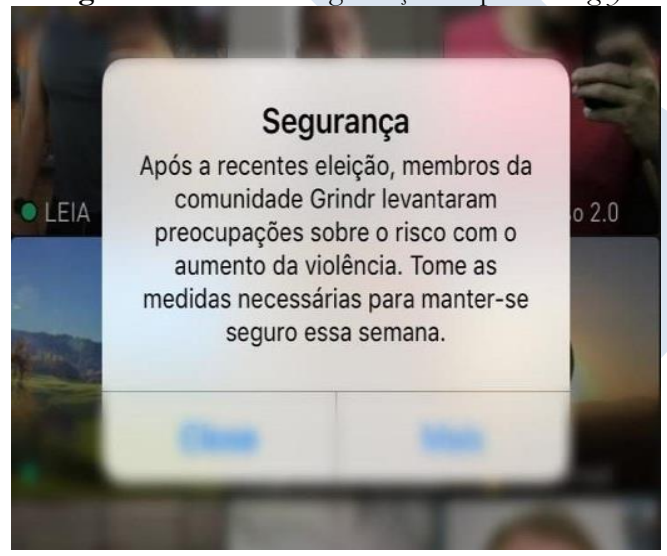

Fonte: Aplicativo Grindr (2018). 
O Grindr é um aplicativo de relacionamento gay criado pelo norte-americano Joel Simkhai, com o intuito de facilitar e aproximar pessoas do mesmo sexo que desejam se conhecer. $\mathrm{O}$ aplicativo filtra as pessoas próximas ao usuário e abre um chat privado para mensagens diretas. O sujeito que disponibiliza de um perfil na comunidade tem a possibilidade de dispor fotos pessoais e colocar pequenos trechos que podem servir como identificação, além de inserir seu resultado de exame de HIV ou de infecções sexualmente transmissíveis (IST's). A ferramenta de localização do aplicativo abre a possibilidade de encontros rápidos, fazendo com que uma pessoa encontre diversos parceiros em um curto espaço de tempo.

Esses encontros rápidos e secretos suscitaram uma discussão aflorada entre membros do aplicativo depois da morte de José Carlos de Oliveira Matos, de 57 anos, morto em seu apartamento, em Curitiba, após conhecidos relatarem que ele tinha marcado encontro com um sujeito também membro do Grindr . No dia do ocorrido o autor do crime se passou pela vítima, José Carlos, e postou em suas redes sociais mensagens de, "Viva a Bolsonaro". A partir desse momento, após membros da comunidade LGBT relatarem insegurança em marcar novos encontros, o próprio aplicativo se responsabilizou em antenar seus usuários por meio de uma mensagem no aplicativo.

O alerta discursiviza, “após a 'recente' eleição, membros da comunidade Grindr levantaram preocupações sobre o risco com o aumento da violência". Esse primeiro trecho revela algumas medidas tomadas pela administração do aplicativo em explanar a situação que os membros relataram, o que se corporifica em uma estratégia biopolítica, no intuito de quantificar e reagrupar sujeitos que estão na mesma situação de vulnerabilidade para assim lançar mão de medidas paliativas no que diz respeito ao bem estar da população ou

${ }^{6}$ Disponível em: <https://poenaroda.com.br/diversidade/gay-curitibano-e-morto-por-assassino-que-exclamaviva-bolsonaro/>. Acesso em: 20 dez. 2018. 
de determinado grupo em situação de risco, mobilizando "dados técnicos, científicos, jurídicos, demográficos, digamos, a grosso modo, sociais, que tornar-se-ão cada vez mais objeto da intervenção governamental” (FOUCAULT, 2008b, p. 194).

Podemos perceber, antes de tudo, a presença de um dispositivo de segurança, criado para alertar a comunidade usuária do aplicativo sobre os ocorridos, seguindo um padrão de controle social e preservação da espécie. Pode-se dizer, numa perspectiva foucaultiana, que o aplicativo lança o comunicado na lógica de diminuir revoltas, o objetivo disso seria assegurar sua existência. Podemos concluir claramente, que o escopo desse comunicado acompanha a ideia dita por Deleuze (1990) sobre a sociedade de controle, na medida em que há estratégias de massificar e unir os sujeitos afetados, na intenção de guiá-los e protegê-los.

A segunda parte do enunciado traz os seguintes dizeres, "Tome as medidas necessárias para manter-se seguro essa semana", percebemos mais uma vez que o verbo "tomar", no imperativo, denota uma medida de alerta, atenção e ordem, baseado nos casos relatado pelos usuários toda a comunidade membro do aplicativo estaria em risco e, portanto, merece atenção e cuidado. O termo "essa semana" faz referência à data em que o aviso veio a público, 11 de outubro de 2018, logo após os resultados das eleições de primeiro turno para presidente, que mostrou uma vantagem significativa para Jair Bolsonaro. Sobre o dizer, "as medidas necessárias", o próprio aplicativo se responsabilizou em guiar o usuário para uma aba do site em que podem ser vistas algumas dicas de cuidado, quais sejam: Não acredite em tudo que vê, proteja sua identidade, não se apresse, diga a um amigo, relate qualquer ataque ou ameaça à polícia, esteja ciente de que outros usuários do aplicativo Grindr podem saber sua localização, entre outras dicas.

Essas dicas são universais e divulgadas como alerta para diversos países em que a homossexualidade é considerada crime ou banida radicalmente, como Rússia, Egito, Arábia Saudita, Nigéria, Libéria, Sudão e Zimbabwe. Visto isso, o Brasil é colocado mais uma vez na rota de fogo dos maiores ataques aos LGBTQ+ desestabilizando a segurança até mesmo em sua própria comunidade, podendo ser invadida a qualquer momento. A sociedade disciplinar tenta mais uma vez, através dessas dicas de segurança, domesticar e pedagogizar os 
sujeitos para que vivam livremente, mas com cautela em relação às particularidades que assinalam sua sexualidade. Nesse momento, o aplicativo incide sobre a manutenção de estratégias de controle, através de uma forma de governar a si mesmo, empreendendo estratégias de segurança pessoal.

Agamben (2002) compreende algumas contradições que as estratégias biopolíticas ostentam, pois existem dois lados referente à atuação desse biopoder, se de um lado o governo propõe medidas de cuidado com a vida de uma parcela da população, do outro, o próprio governo intensifica técnicas para eliminar os sujeitos marginalizados pela sociedade, sejam eles: negros, indígenas ou LGBTQ+. Nas palavras do autor supracitado, “[...] 'o belo dia' da vida só poderá obter cidadania política através do sangue e da morte ou na perfeita insensatez a que a condena na sociedade do espetáculo" (AGAMBEN, 2002, p. 19).

Figura 3 - Folder sobre como reagir em caso de agressões ao público LGBTQ+

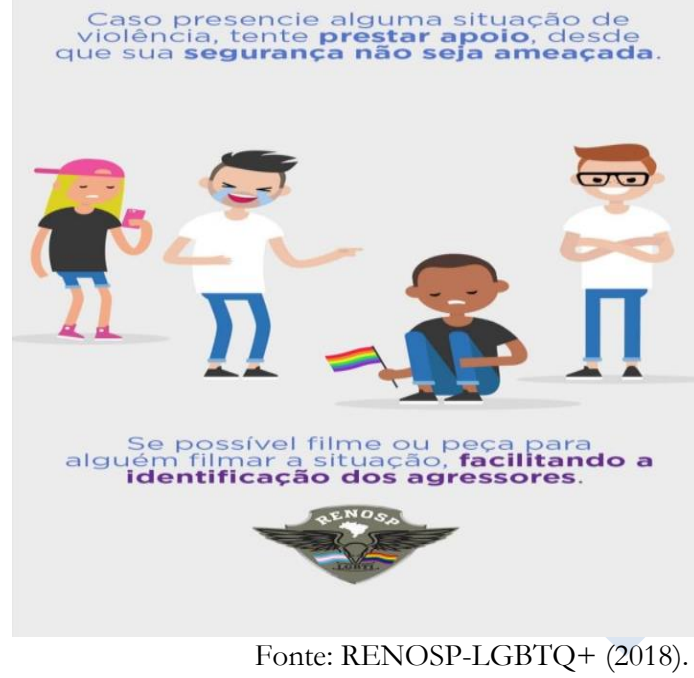


Considerando o cenário político e as ameaças constantes aos LGBTIs, a RENOSP_LGBTI elaborou uma cartilha com dicas de segurança para alertar esses sujeitos quando estiverem em ambiente público, considerando os diversos nichos da população. A cartilha foi divulgada em 24 de outubro de 2018, véspera das eleições de segundo turno para presidente do Brasil. Além disso, as pesquisas eleitorais mostravam um avanço considerável e uma vitória iminente do candidato do PSL, Jair Bolsonaro, em relação a Fernando Haddad (PT).

Podemos observar na imagem quatro sujeitos, dois deles vestidos de branco que parecem ridicularizar o garoto de camisa preta que se encontra de cócoras hasteando uma pequena bandeira LGBTQ+ (as 7 cores do arco-íris). Outro garoto, também de camisa preta parece se comover com a cena, mas em referência ao que o enunciado diz, ele apenas estende o celular para registrar a situação e poder tomar providências cabíveis. Os garotos de camisa branca que estão ferindo a dignidade humana do outro sujeito estão se divertindo com a situação. Ao observarmos a imagem, podemos perceber padrões de beleza comuns a comunidade heteronormativa, já em relação ao que filma, percebemos uma desconstrução dos estereótipos tidos como "masculinos".

O enunciado contido na figura 3 refere-se à violência efetivada. Como nas outras materialidades a pauta era a prevenção contra atos agressivos, essa última traz estratégias a serem tomadas caso se presencie algum LGBTQ+ sendo alvo de injúrias ou espancamentos. O enunciado cria uma medida de intervenção, caso seja possível, "tente prestar apoio”, mas logo depois enfatiza que a sua segurança deve ser respeitada, "desde que sua segurança não seja ameaçada". Mais uma vez o enunciado da cartilha propõe uma intervenção por meio da tecnologia dos smartphones, uma estratégia possível sugerida para que os agressores sejam identificados e indiciados, como se observa no enunciado, "Filme ou peça para alguém filmar".

Na aula de 17 de março de 1976, no livro Em defesa da sociedade, Foucault (2005) tece comentários acerca do racismo de estado, repartindo em duas funções, a primeira diz que o racismo divide e promove cesuras no intuito de fragmentar a população, baseado apenas 
e somente no domínio biológico, acreditando que isso trará exclusões, caso não siga padrões considerados "normais". Por outro lado, esse racismo reaviva a sociedade de soberania, já que se pauta na ação do "fazer morrer e deixar viver", baseada no intuito de que "para viver, é preciso que o outro morra". Nas palavras de Foucault (2005),

A morte do outro não é simplesmente a minha vida, na medida em que seria minha segurança pessoal; a morte do outro, a morte da raça ruim, da raça inferior (ou do degenerado, ou do anormal), é que vai deixar a vida em geral mais sadia; mais sadia e mais pura. (FOUCAULT, 2005, p. 305)

Entendendo essa sociedade de soberania e também o racismo de estado verificado por Foucault (IBID.), podemos colocar em cheque a heteronormatividade compulsória, descrita por Butler (2003), quando a classe humana predominante e digna de viver é a heterossexual, compreendendo que é a única que deve existir. Relacionando com a cartilha, podemos identificar que a frequência com que as agressões ocorrem ao público LGBT, reacende o teor da sociedade de soberania, considerando isso, a cartilha busca direcionar o determinado público a um cuidado e uma atenção especial a momentos como esse, lançando estratégias de resistência.

Diante do exposto, podemos observar que os enunciados contidos na cartilha de segurança ao público LGBT apresentam-se como índices determinantes do biopoder e das estratégias biopolíticas. Podemos compreender por biopoder aquilo que, "tomou posse da vida [...] que conseguiu cobrir toda a superfície que se estende do orgânico ao biológico, do corpo à população, mediante o jogo duplo das tecnologias de disciplina, de uma parte, e das tecnologias de regulamentação, de outra" (FOUCAULT, 2005, p. 302). Observamos, portanto, que no cerne da construção dos discursos em torno da segurança da comunidade LGBTQ+, está presente um cuidado que deve ser gerado por si e para os outros, guiados pelas palavras de ordem e cuidado, para efetivar-se o governo dos povos e as estratégias biopolíticas, no intuito de conservação da sociedade disciplinar, na lógica de "fazer viver e deixar morrer". 
Considerando a baixa expectativa de vida para o público LGBTQ+ e ainda mais baixa para travestis e transexuais, 35 anos (ANTRA), em relação à média populacional, as cartilhas são construídas no intuito de lançar estratégias de conservação da vida, compreendendo as fragilidades de cada nicho populacional, que não deve, assim, ser esquecida ou "fazê-las morrer".

\section{Notas finais}

Sendo assim, o nosso propósito com esse escrito incidiu em analisar os discursos que enunciam acerca da segurança dos sujeitos LGBTQ+, com o intuito de investigar o funcionamento das estratégias biopolíticas no que tange à manutenção e à seguridade das vítimas de homofobia no Brasil. Para efetivar esse objetivo, lançamos um olhar analítico acerca de três materialidades que discursivizam essa questão. Embora essas materialidades estejam disponíveis em diferentes formatos, todas elas compartilham de um mesmo propósito: alertar a população LGBTQ+ sobre procedimentos de segurança e bem-estar. Em uma das materialidades a segurança pode ser aliada ao conhecimento sobre seus direitos enquanto cidadão, a exemplo da revista em sujeitos transsexuais e travestis, muitas vezes o setor especializado para os proteger, acaba por disseminar atitudes LGBTQfóbicas, em se tratando da dinâmica em que mulher revista mulher, o que não indefere se é cis ou trans.

Outras questões que se relacionam com a sociedade de controle vigente é o fato de haver uma divulgação massiva sobre procedimentos de segurança e cuidados de si para os LGBTQ+. Há uma rede de saber-poder que pedagogiza o comportamento humano frente a situações de perigo, como por exemplo, a materialidade que alerta toda a comunidade alvo de agressões, incentivando filmar e denunciar. O objetivo das estratégias identificadas nas materialidades consiste no funcionamento do maquinário biopolítico que compõe, alinha e esquadrinha o corpo populacional no intuito de conduzi-lo. Esses sujeitos encontram-se às margens da sociedade, que intensifica a "sociedade de soberania" apenas para sujeitos que não pertencem a uma lógica padrão, ou seja, héteros, branco e cis. 
Vimos então, que as estratégias biopolíticas presentes nas materialidades analisadas não funcionam com a finalidade de acabar com a LGBTQfobia no Brasil. Para isso, medidas mais severas advindas do governo federal e do Superior Tribunal de Justiça (STF) teriam que se consolidar. Ainda no aguardo desse encaminhamento, o material analisado cumpre o papel do governo, pois age para atenuar a problemática de modo mais rápido, por meio da pedagogização das vítimas do preconceito, numa rede de acolhimento segundo a qual o sujeito LGBTQ+ não está sozinho.

\section{YOU ARE NOT ALONE! BIOPOLYTIC STRATEGIES IN DISCUSSIONS ON LGBTQ + SUBJECT SECURITY}

ABSTRACT: According to recent researches accomplished by Group Gay of the Bahia (GGB), a LGBTQ+ is dead every 20 hours in the Brazil, which evidence our country as one of which more kill these subjects in the world, overcoming, including, countries in that these sexualities are condemned. Thinking for this bias, it is important to detach that the elections of 2018 did to emerge a series of speeches LGBTQphobic starting of the current President of the republic, Jair Bolsonaro. The statistic datas of the GGB and the lack of commitment announced yet in campaign by President, did with that associations non-governmental, sites and gay apps proposed the its own precautionary measures, in order that this number aggravating of dead did not increase. Taking this assumption as base, the present study aim to analyse the speeches that enunciate about of the security of the LGBTQ+ subjects, starting of an archaeogenealogical look proposed by Michel Foucault, considering the concepts of Biopower and Biopolitics that break out in the detached materiality. Consequently, the analysis approach of the society logic of control in the that sound the emergence of measures of protection for the subjects that did not obey the binary logic of genre and of sexual orientation.

KEYWORDS: Security; LGBTQ+; Biopower; Biopolitics

\section{REFERÊNCIAS}

ANTRA. Mapa dos assassinatos de transexuais e travestis no Brasil em 2017. Disponível em: <https://goo.gl/bDgQpM>. Acesso em: 17 dez. 2018.

BAZZICALUPO, Laura. Biopolítica: um mapa conceitual. Trad. Luísa Rabolini. São Leopoldo, RS: Ed. Unisinos, 2017.

BUTLER, Judith. Problemas de gênero: Feminismo e subversão da identidade. Tradução, Renato Aguiar. Rio de Janeiro: Civilização Brasileira, 2003.

FOUCAULT, Michel. As formações discursivas. IN: A Arqueologia do Saber. $8^{a}$ edição, Rio de Janeiro: Forense Universitária, 2012, p. 47. 
. O nascimento da biopolitica: curso dado no collège de France (1978-1979). São Paulo, Martins Fonte, 2008a.

. Segurança, território e população. Curso dado no Collège de France (1977-1978). São Paulo: Martins Fontes, 2008b.

. História da Sexualidade I: a vontade de saber. São Paulo, SP: Graal Edições. 2007. Em defesa da sociedade: collège de France (1974-1976). São Paulo, Martins Fontes, 2005. Os anormais. São Paulo: Martins Fonte, 2001.

. A governamentalidade. In: FOUCAULT, Michel. Microfisica do poder. Rio de Janeiro: Graal, 1998, p. 277 - 293.

GRUPO GAY DA BAHIA. Disponível em: < https://grupogaydabahia.com.br/>. Acesso em: 17 dez. 2018.

KRUG, Etienne et al. (eds.). World report on violence and health. Geneva: World Health Organization, 2002.

LAURO, Rafael. Deleuze - sociedade de controle. Disponível em: <https://razaoinadequada.com/2017/06/11/deleuze-sociedade-de-controle/>. Acesso em: 17 dez. 2018.

PANIAGO, Maria de lourdes. Das sociedades de soberania às sociedades do controle: uma abordagem foucaultiana. Disponível em: < http://www.congressohistoriajatai.org/anais2007/doc\%20(39).pdf >. Acesso em 20/01/2019.

RUBIN, G. Thinking sex: Notes for a radical theory of the politics of sexuality. In: VANCE, C. S. (Org.). Pleasure and danger: Exploring female sexuality. Londres: Routledge, 1984.

SEIXAS, Rogério Luís da Rocha. Ethos crítico e governamentalidade em Michael Foucault. Revista Dialectus, ano 5, n.13, 2017.

SILVA, Maria Amarilda Ribeiro Borges da; SANCHES, Mário Antônio. Não desista de ser feliz: Um ensaio sobre a permanência de mulheres em relacionamentos com homens violentos. Caderno teológico da PUCPR, Curitiba, v.2, n.1, p. 113-134, 2014.

SOUZA, Daniel Cerdeira et al. Assassinatos de LGBTs no Brasil - uma análise de literatura entre 2010-2017. Periódicus, Salvador, n.10, v. 1, nov.2018-abr. 2019.

SANTOS, Paulo Reis. Tensões e desafios: LGBTS e o poder público?. Revista de Psicologia. UNESP 9(2), 2010. 